\title{
A meta-analysis of the executive function components inhibition, shifting, and attention in intellectual disabilities
}

\author{
M. Spaniol ${ }^{1,2}$ (D) \& H. Danielsson ${ }^{3,4}$ (D) \\ I Cognitive Science, Osnabrück University, Osnabrück, Germany \\ 2 Faculty of Medicine, University of Cologne and Department of Psychiatry, University Hospital Cologne, Cologne, Germany \\ 3 Department of Behavioural Sciences and Learning, Linköping University, Linköping, Sweden \\ 4 Swedish Institute for Disability Research, Linköping University, Linköping, Sweden
}

\begin{abstract}
Background Executive function is a concept for higher-order cognitive functions, which have the role of controller and modulator of cognitive abilities. The consensus in the literature is that people with an intellectual disability perform significantly lower on executive function tasks than groups matched on chronological age. The comparison with groups matched on mental age is less clear. Therefore, the objective of this meta-analysis was to investigate to what extent executive function is impaired in people with intellectual disability compared with a typically developing control group matched on mental age. It was also investigated if the executive function component and intellectual disability aetiology moderated the effect.

Methods Eligibility criteria were participants with intellectual disability (IQ $\leq 75$ ) without a dual diagnosis; a comparison group matched on mental age; executive function outcome reported in a group comparison study design with $n \geq$ IO. Working
\end{abstract}

Correspondence: Malin Spaniol, Faculty of Medicine, University of Cologne and Department of Psychiatry, University Hospital Cologne, Kerpener Strasse 62, 50937 Cologne, Germany (e-mail: malin.spaniol@uk-koeln.de). memory tasks and ratings of executive function were not included. The literature search yielded 6637 potentially interesting articles. Twenty-six studies (with 99 effect sizes) including I395 participants were included in the quantitative synthesis.

Results A multilevel random-effects meta-analysis found that people with intellectual disability performed statistically significantly lower than the mental age-matched group on the executive function tasks, $g=-0.34,95 \%$ confidence interval $=[-0.53,-0 . \mathrm{I} 6]$. However, the heterogeneity between effect sizes was large. The intellectual disability aetiology moderator was significant, but it only reduced the heterogeneity marginally.

Conclusion The overall conclusion is that individuals with an intellectual disability have more problems with executive function tasks than mental age-matched controls. Limitations are the large unexplained variance and the remarkably high number (69) of different tests that were used, which make more detailed conclusions problematic. This meta-analysis implies that future studies need to be of better quality, to have higher power, and to a higher degree use the same executive function tests.

Keywords Attention, Executive function, Inhibition, Intellectual disability, Shifting

(C) 202 I The Authors. Journal of Intellectual Disability Research published by MENCAP and International Association of the Scientific Study of Intellectual and Developmental Disibilities and John Wiley \& Sons Ltd.

This is an open access article under the terms of the Creative Commons Attribution License, which permits use, distribution and reproduction in any medium, provided the original work is properly cited. 
Journal of Intellectual Disability Research

M. Spaniol \& H. Danielsson - Meta-analysis of executive functions

\section{Background}

\section{Rationale}

People with an intellectual disability (ID) have low performance on executive function (EF) tasks (Danielsson et al. 2010; Costanzo et al. 2013), but the results are heterogeneous. One way to find overall patterns and investigate potential moderators that can explain differences in results is to conduct a meta-analysis (Lipsey and Wilson 200I).

Therefore, the present study aimed to conduct a systematic review with an additional meta-analysis on $\mathrm{EF}$ in ID.

Executive function, which also can be called executive control or cognitive control, refers to a family of top-down mental processes needed when you must concentrate and pay attention, according to Diamond (2013). Different researchers have different views on whether EF is a unitary construct, a multifaceted construct, or both. Some argue that EF refers to several distinct abilities, which are only loosely related; others claim that there is one underlying ability, which is responsible for all EF abilities (Blair et al. 2005, pp. 192-193). However, the consensus in the literature is that EF consists of separated but related cognitive processes (Maricle and Avirett 2012). A similar view is presented in one of the most cited studies in the EF literature (Miyake et al. 2000). They treat inhibition, shifting and updating as the three target EF components, which are 'not completely independent and seem to share some underlying commonality' and therefore indicate both unity and diversity of EF (Miyake et al. 2000). Other studies (e.g. Menghini et al. 2010; Costanzo et al. 2013) use a broader definition which includes attention. In conclusion, EF can be defined in many ways and the different definitions are typically vague.

For the scope of this article, we needed a definition of EF with clear boundaries so that the search and coding of articles could be efficient. To avoid the problem of the vague EF definitions, we have defined $\mathrm{EF}$ as having the components attention, inhibition, shifting and updating. That is, EF as an umbrella term is not defined beyond the components, which will be defined in the coming paragraphs. Only laboratory measures of EF will be included because subjective ratings and measures of cognition correlate very low (refer to e.g. a meta-analysis on memory with $r=0.06$ Crumley et al. 20I4).
Attention refers to all aspects of human cognition that a person can control, and all aspects of cognition related to limited resources or capacity dealing with that, which is close to the Shiffrin (I988) definition. Attention can be further divided into for example selective attention, sustained attention, and self-regulatory attention.

The definitions of inhibition and shifting are in line with the Miyake et al. (2000) definition. Inhibition is defined as the ability to deliberately suppress an inappropriate, automatic response. Typical inhibition tasks include stroop and go/no-go tasks. Different Tower tasks belong to inhibition, following Miyake et al. (2000), even though some papers treat them as planning or problem-solving tasks. Shifting is the ability to switch or change between rules or tasks efficiently. Design fluency switching tasks and card sorting tasks with rule switching are included in shifting.

Updating involves active updating of information and decisions that are made on the updated information. This definition will exclude typical working memory tasks like dual-task span tasks. This is a deliberate choice because many test batteries for IQ include tests of working memory or short-term memory. Therefore, those tasks are part of the definition of the ID group. To avoid this methodological challenge and to make sure that the other EF tasks are not only a small part of the larger literature on working memory in ID (refer to for example a meta-analysis on EF in Down syndrome where short-term memory and working memory tasks accounted for $74 \%$ of their studies Tungate and Conners 202I), working memory tasks were not included in our definition of EF. Additionally, different aspects of working memory in people with ID are already summarised, for example, an integrative review (Lifshitz et al. 2016), book chapters (Henry 20II), and a meta-analysis of working memory training (Danielsson et al. 2015). One example of an updating task that is included in our definition is the N-back task, where the participant is to judge if one item (in a serially presented stream of items) is the same as the item presented $\mathrm{N}$ positions earlier (e.g. two positions earlier). In this task, the information needs to be updated after every item, and the decision is taken on the updated information.

No cognitive abilities can be measured without dependency on other cognitive abilities. This is also

(C) 202 I The Authors. Journal of Intellectual Disability Research published by MENCAP and International Association of the Scientific Study of Intellectual and Developmental Disibilities and John Wiley \& Sons Ltd. 
M. Spaniol \& H. Danielsson - Meta-analysis of executive functions

true for EF, something that Miyake et al. (2000) called the task impurity problem. Even though the non-specific EF tasks lack specificity and sometimes even sensitivity, they are claimed to be well suited to assess severe EF deficits (Snyder et al. 2015). To handle this problem in the meta-analysis, tasks that to a large degree depend on several EF components were included in the EF component 'combination'. Examples of tasks in this category are planning tasks, fluency tasks, and card sorting tasks.

In studies on people with ID, it is common to have a comparison group matched on mental age. This is based on the idea that ID is a delayed development and if the ID group is compared with a group matched on mental age (from here MA controls), the groups should perform on par, for more details, refer to, for example, Zigler and Balla (I982). In other words, the prediction based on the delayed development model would be to get an effect size of zero in this meta-analysis. The concept of mental age has been criticised (Thurstone 1926) and using comparison groups matched on mental age has its limitations (Burack et al. 2004; Jarrold and Brock 2004). However, most studies on EF in people with ID use a mental age comparison group as it is still the best available choice to investigate if a specific ability is delayed compared with general cognitive ability (Messer et al. 202 I). Therefore, mental age will be the comparison group used in this meta-analysis.

Most EF studies on people with ID include one of the following experimental groups: ID with non-specific cause (NSID), Down syndrome (DS), Williams syndrome (WS) or Fragile X syndrome (FXS). Cross syndrome studies indicate differences between cognitive profiles of the four subtypes where NSID have a homogenous cognitive profile and the syndrome specific profiles seem to have clearer strengths and weaknesses, for example, people with DS and FXS perform well on visuospatial tasks (Kogan et al. 2004) and people with WS perform well on verbal tasks (Costanzo et al. 2013). The differences between the groups' general cognitive profiles have also been found in studies on EF (Carney et al. 20I3; Danielsson et al. 20I6) even though studies with ID groups of different aetiologies are rare. For all these reasons, the low performance of the ID group on EF tasks can sometimes be explained by genetic factors, other times by an overall low intelligence level, as suggested by Lanfranchi et al. (2010). To investigate this further, ID aetiology will be included as a moderator.

\section{Objectives}

To the best of our knowledge, no meta-analysis has been conducted on EF in people with ID without dual diagnosis so far. Therefore, this work unified and analysed the research, which has already been conducted. This was further specified in the following research questions:

- Do people with ID have impaired EF compared with MA controls?

- Do EF component and ID aetiology moderate the effect?

Overall, we expected to find a medium to large effect size. We expected a large heterogeneity between the effect sizes that could partly be explained by moderators.

\section{Methods}

This article follows an open science approach (e.g. Klein et al. 2018) by having material (full documentation of searches, search files, full-text screening exclusion for all articles), the dataset (coding of the included articles) and analysis code openly available online (http://doi.org/IO.I7605/OSF. IO/NJSD3). The analysis was not preregistered.

\section{Information sources, search and study selection}

For the identification of relevant studies, a literature search was conducted in the databases PubMed, Scopus, PsycINFO and Web of Science (core collection). The literature search (last updated 2I August 2019) was based on free text and predefined search words (different for each database) related to 'intellectual disability' AND 'executive function' with limitations to journal articles in English. A full search strategy for all databases can be found in http://doi. org/IO.I7605/OSF.IO/NJSD3.

The process in the meta-analysis followed the PRISMA model (Liberati et al. 2009) and included four main steps: identification, screening, eligibility and inclusion, for details, refer to the PRISMA flow diagram in Figure $I$ that is adapted from

(C) 202 I The Authors. Journal of Intellectual Disability Research published by MENCAP and International Association of the Scientific Study of Intellectual and Developmental Disibilities and John Wiley \& Sons Ltd. 
M. Spaniol \& H. Danielsson - Meta-analysis of executive functions
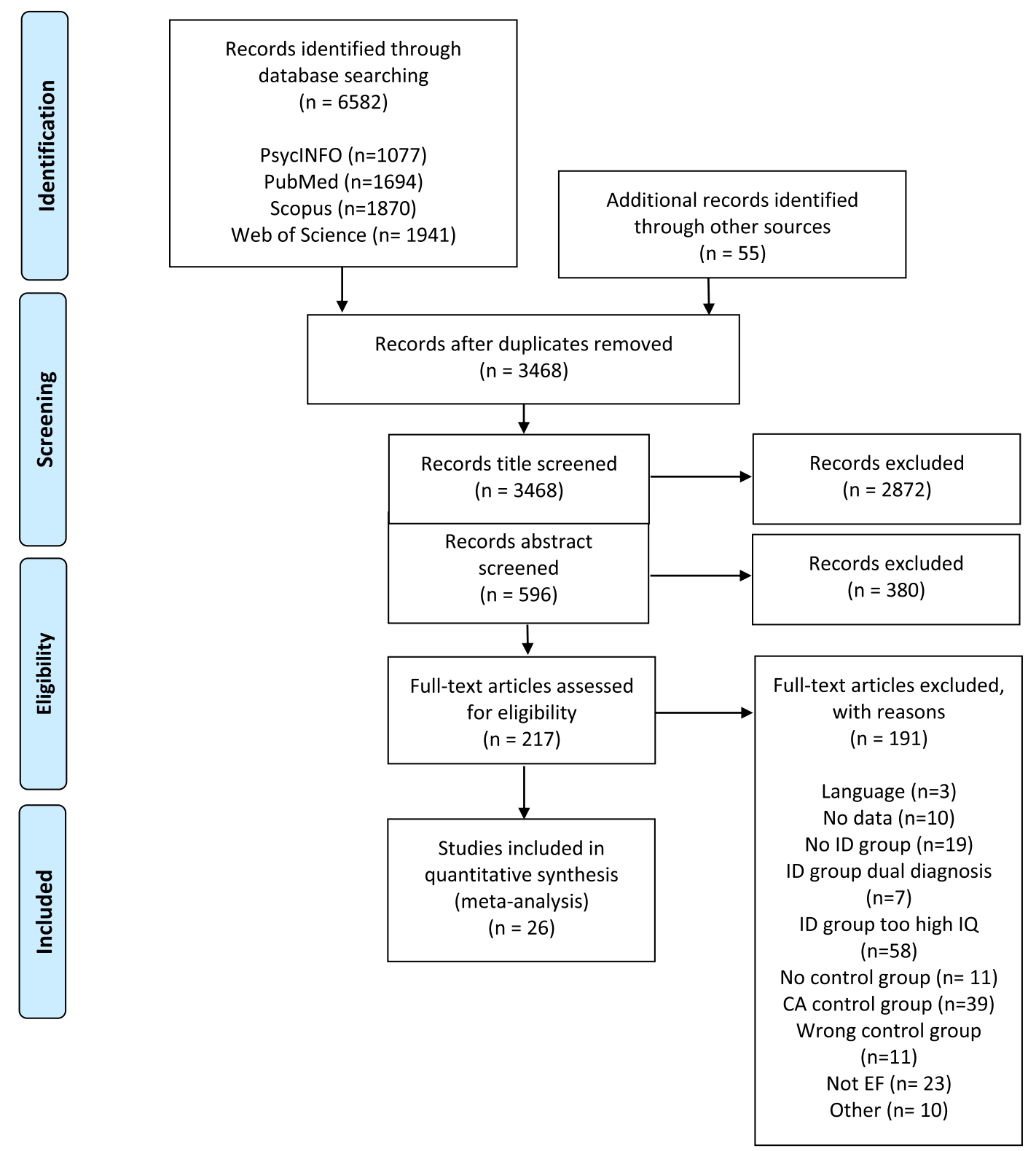

Figure I. PRISMA flow diagram. [Colour figure can be viewed at wileyonlinelibrary.com]

(Moher et al. 2009) and the PRISMA checklist in Appendix A. The search for all four databases yielded 6582 potentially relevant results. Reference lists of finally included articles were scanned. Also, grey literature was requested at the European Conference on Psychological Theory and Research on Intellectual and Developmental Disabilities in Padua 2018, and authors who had published articles on EF in ID were contacted via email and asked for additional data, matching the criteria. This led to 55 additional records. The total number after all duplicates that were removed was 3468 . The number of full-text articles assessed for eligibility was 217. Twenty-six of all papers met the inclusion criteria. The other articles had to be excluded due to various reasons; refer to Figure I for details. All records in the title screening and abstract screening were assessed by at least one of three reviewers (H. D., M.S. and M.A.). If the

(C) 202 I The Authors. Journal of Intellectual Disability Research published by MENCAP and International Association of the Scientific Study of Intellectual and Developmental Disibilities and John Wiley \& Sons Ltd. 
Journal of Intellectual Disability Research

M. Spaniol \& H. Danielsson - Meta-analysis of executive functions

reviewer was uncertain, the record was included in the next round of screenings. The full-text screening was performed by two reviewers (H.D. and M.S.) and then checked by the other reviewer. Disagreements were solved by discussion. The coding of the articles was conducted by two coders (H.D. and M.S.) and checked for plausibility by the coders. Functions from the $\mathrm{R}$ packages Metagear (Lajeunesse 2016) and Revtools (Westgate 20I9) were used to identify duplicates and to distribute the screening among the reviewers in the screening process.

\section{Eligibility criteria}

Studies had to meet (and report) the following criteria, in P(I)COS format (I for Intervention was not relevant), to be included in the present metaanalysis-participants: reported $\mathrm{IQ}_{\max } \leq 75$ of an ID group (including syndromes associated with an ID, e.g. DS, WS or FXS) without a dual diagnosis (such as ASD, ADHD, learning disability and dementia); Comparison: include a comparison group (without disabilities) matched on mental age (based on a standardised test); outcome: results on (our definition of) EF (attention, inhibition, shifting, updating and similar, but not working memory dual tasks, theory of mind tests) were reported with enough information to calculate an effect size; study design: group comparison with $\geq_{\text {IO }}$ participants per group.

Intellectual disability is generally defined as having IQ $<70$, but given that there is an estimated margin of error of 5 points, which should be considered when making a diagnosis of ID (Schalock et al. 2010), we have used $\mathrm{IQ}_{\max } \leq 75$ as our criterion. Many studies have not reported $I Q_{\max }$ or IQ at all. To include more studies, $\mathrm{IQ}_{\max }$ has been estimated where it is not reported. IQ was estimated as I00* mental age/chronological age (for $\mathrm{CA}<20$ years). If $\mathrm{IQ}_{\max }$ was not reported, it was estimated as $\mathrm{IQ}_{\text {mean }}+{ }^{\star}{ } \mathrm{IQ}_{\mathrm{SD}}$ if possible. If this also was not possible, studies with $\mathrm{IQ}_{\text {mean }}<50$ were estimated to have $\mathrm{IQ}_{\max } \leq 75$ and were also included.

\section{Data collection process}

To make analyses possible, different variables were extracted from the studies. They can be divided into demographic variables (publication year, sex ratio, chronological age, mental age, IQ and ID aetiology) and methodological variables (sample size, EF test used, EF component and domain). Not all data were available for all studies. When a paper tested multiple ID groups, all ID groups that met the inclusion criteria were coded separately. When several EF measures were used in a paper, the most relevant measure (e.g. accuracy) was used if several measures were given for one test, but if the measures belonged to different tests, all effect sizes were included, even if they claimed to measure the same EF component.

The coding of the EF components used the categories shifting, updating, inhibition, attention and combination. The categories follow our definition of $\mathrm{EF}$ and are an attempt to get some rough division of EF. The coding was hard to do because many tests claim to measure several EF components, and even when the same test was used in several studies, it was claimed to measure different aspects of EF.

\section{Risk of bias in individual studies}

It is recommended that meta-analyses include a risk of bias assessment to get an overview of the quality of the individual articles, which can be a base for analysis if the quality of the articles influences the results. Quality appraisal tools are commonly suitable for one specific design, for example, intervention studies, cohort studies or correlational studies. There is, however, to the best of our knowledge, no quality appraisal tool for the type of design (group comparisons) that this article is about. Therefore, we have created a short tool with four questions, influenced by several quality appraisal tools. The questions were (I) are the groups well matched on mental age? (2) Does the study have good statistical power? (3) Was the reliability of the test reported? and (4) Is the test used established? For each question, a score (range o-2) was given and then a quality index was calculated as the sum of those scores (o-8). The matching on mental age was calculated as an effect size of the group difference, where an absolute group difference (in Cohen's $d$ ) of $<0.20$ gave the score $2,<0.40$ gave the score $\mathrm{I}$, and score 0 was for studies with larger differences or studies where this could not be calculated because of lack of reporting. Statistical power was calculated for detecting a directional medium effect (Cohen's $d=0.5$ ). Each effect got a score of 2 if the statistical power was $>80 \%$ power, $\mathrm{I}$ if it was $>50 \%$; and $\mathrm{O}$ if it was $<50 \%$. A reliability score of 2 was for studies that reported some type of reliability (e.g. Cronbach's

(C) 202 I The Authors. Journal of Intellectual Disability Research published by MENCAP and International Association of the Scientific Study of Intellectual and Developmental Disibilities and John Wiley \& Sons Ltd. 
M. Spaniol \& H. Danielsson - Meta-analysis of executive functions

alpha or test-retest reliability) for the test of the study sample, a score of $\mathrm{I}$ of the tests reliability was reported on another sample, and o if it was not reported at all. For the last quality question, a score of 2 was given if the test used was referenced in the text, $\mathrm{I}$ if the test was an adaption of a referenced test and $o$ if the test was new or not referenced at all.

\section{Statistical analysis}

The data was analysed using the Metafor package (Viechtbauer 20I0) in R (R Core Team 20I9) using $\mathrm{R}$ studio software (RStudio Team 20I6) and the manuscript was formatted using papaja (Aust and Barth 20I8) and citr (Aust 20I8). We calculated each study's effect size Hedges' $g$, as recommended by Borenstein et al. (2009), based on means, SDs and $n$, with the MA controls as the reference group. For some effect sizes, the direction of the scale was reversed at the individual measurement level, so that negative effect size values reflected lower performance for the group with ID. The mean effect over all samples was estimated using the restricted maximum likelihood approach, as recommended by Van den Noortgate et al. (2013).

Many studies reported more than one effect size. To handle this dependency between effect sizes, a multilevel random-effects meta-analysis approach, as recommended by Assink and Wibbelink (2016), was used. This approach has one random effect for each study as an addition to the random effect for each effect size. The likelihood ratio tests yielded that the fit of the multilevel model was significantly better than the fit of the reduced models $\left(\mathrm{AIC}_{\text {full model }}=\mathrm{I} 87.90\right.$, $\mathrm{AIC}_{\text {reduced model without between-studies variance }}=238.99$, $\mathrm{AIC}_{\text {reduced model without within-studies variance }}=\mathrm{I}$ 96.2I).

Therefore, the multilevel random-effects analysis was used for all analyses.

The effect size heterogeneity was tested with the Metafor package's version of Cochran's Q test. How much of the total variation across studies was due to heterogeneity rather than sampling error (Higgins and Thompson 2002) is presented as a percentage $\left(I^{2}\right)$ for both level 2 (variance within studies) and level 3 (variance between studies). Moderator analyses were conducted to test our second research question, using the coded variables ID aetiology and EF component as moderators. Subgroup analyses were carried out for significant moderators. Further, exploratory moderator analyses were conducted on domain, chronological age, mental age and IQ.

It is recommended that publication bias is assessed with a variety of methods (Carter et al. 2017).

However, only two methods were available for multilevel models in the Metafor package, so only a funnel plot and the rank correlation test examining Kendall's tau were used. For funnel plot analysis, asynchrony is an indicator of publication bias (Sterne et al. 20I I). As a measure of sensitivity, Cook's distance was used to investigate potential outliers, with a cut-off of I, as recommended by Cook (I979). Statistical power was calculated with the pwr package in $\mathrm{r}$ (Champely 2020) as a directional effect for a $t$ test with two groups.

\section{Results}

The coded information for each effect size included in the study can be found in Tables I and 2 and the full references to the included articles are marked with * in the reference list. The 26 studies included in this meta-analysis were published across 16 different journals with the median publication year 2012 (1962-2020). The study means were weighted by the number of participants in each study. There were 1395 participants included, 677 with ID (55\% male participants) and 7I $8 \mathrm{MA}$-controls (55\% male participants). The median number of ID participants was 2 I (range 10-65), which equals having $80 \%$ power to detect group differences of Cohen's $d=-0.34$. The ID participants had mean chronological age of I 8.83 years [range of study means $4.34-49.88$ ], mean mental age of 6.3I years [I.88-II.I7] and mean IQ of 46.50 [19.92-65.75]. The MA-controls had mean chronological age of 6.25 years [range of study means I.93-II.I7], mean mental age of 6.23 years [I.93-II.I7], and mean IQ of I08.8I [94-I24].

Out of the 99 included effect sizes, I 6 belonged to attention, 37 to inhibition and 24 to shifting measures. There was only one study measuring updating, which is probably because our definition of EF excluded working memory tests, which other definitions of EF consider to be updating. In the moderator analyses, the updating study will be part of the category combination. Twenty-one effect sizes were categorised as combination which mostly included tests of planning, sorting and fluency. There was a large variety of tests used to assess EF. 
M. Spaniol \& H. Danielsson - Meta-analysis of executive functions

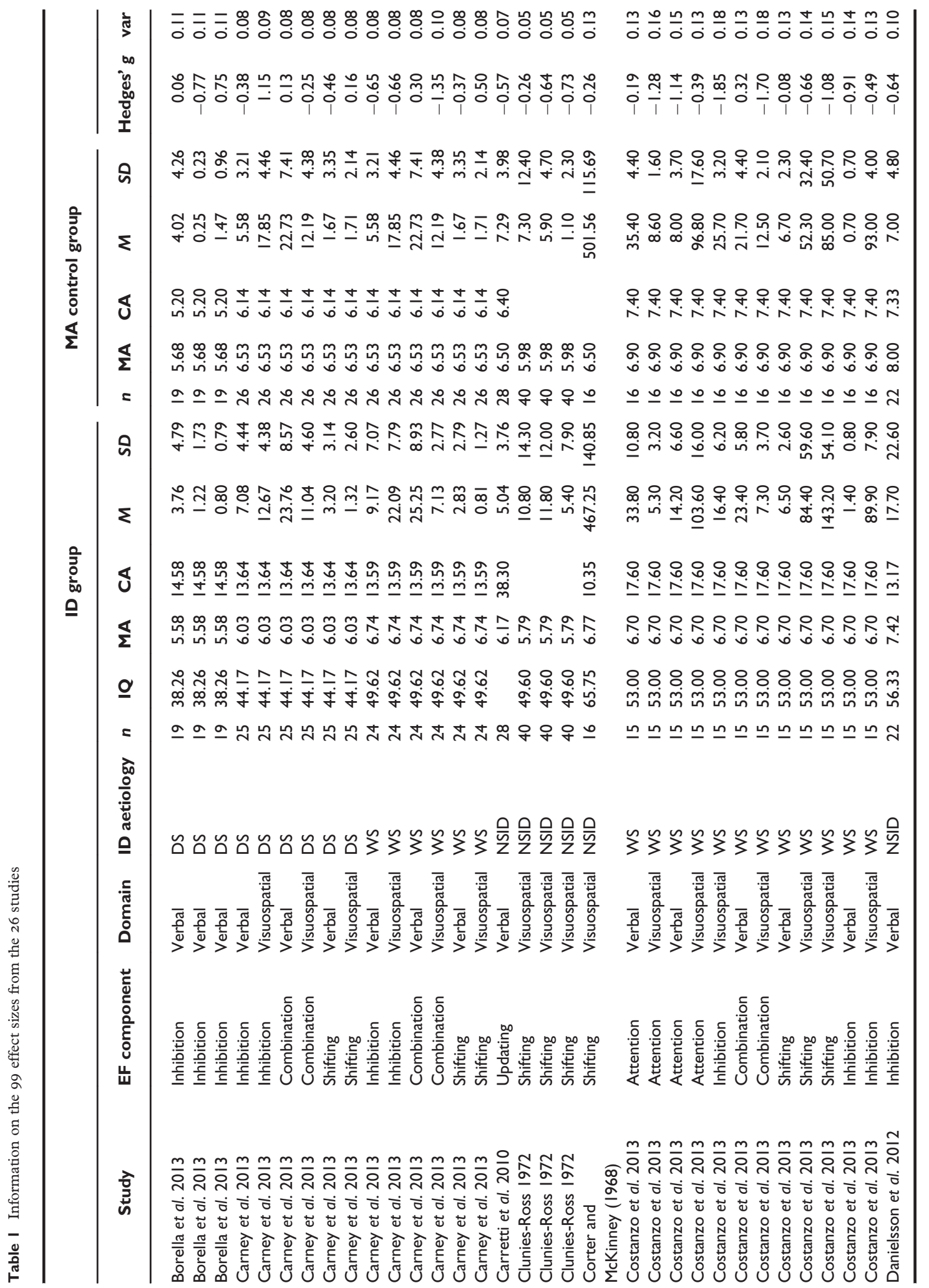

(C) 202 I The Authors. Journal of Intellectual Disability Research published by MENCAP and International Association of the Scientific Study of Intellectual and Developmental Disibilities and John Wiley \& Sons Ltd. 


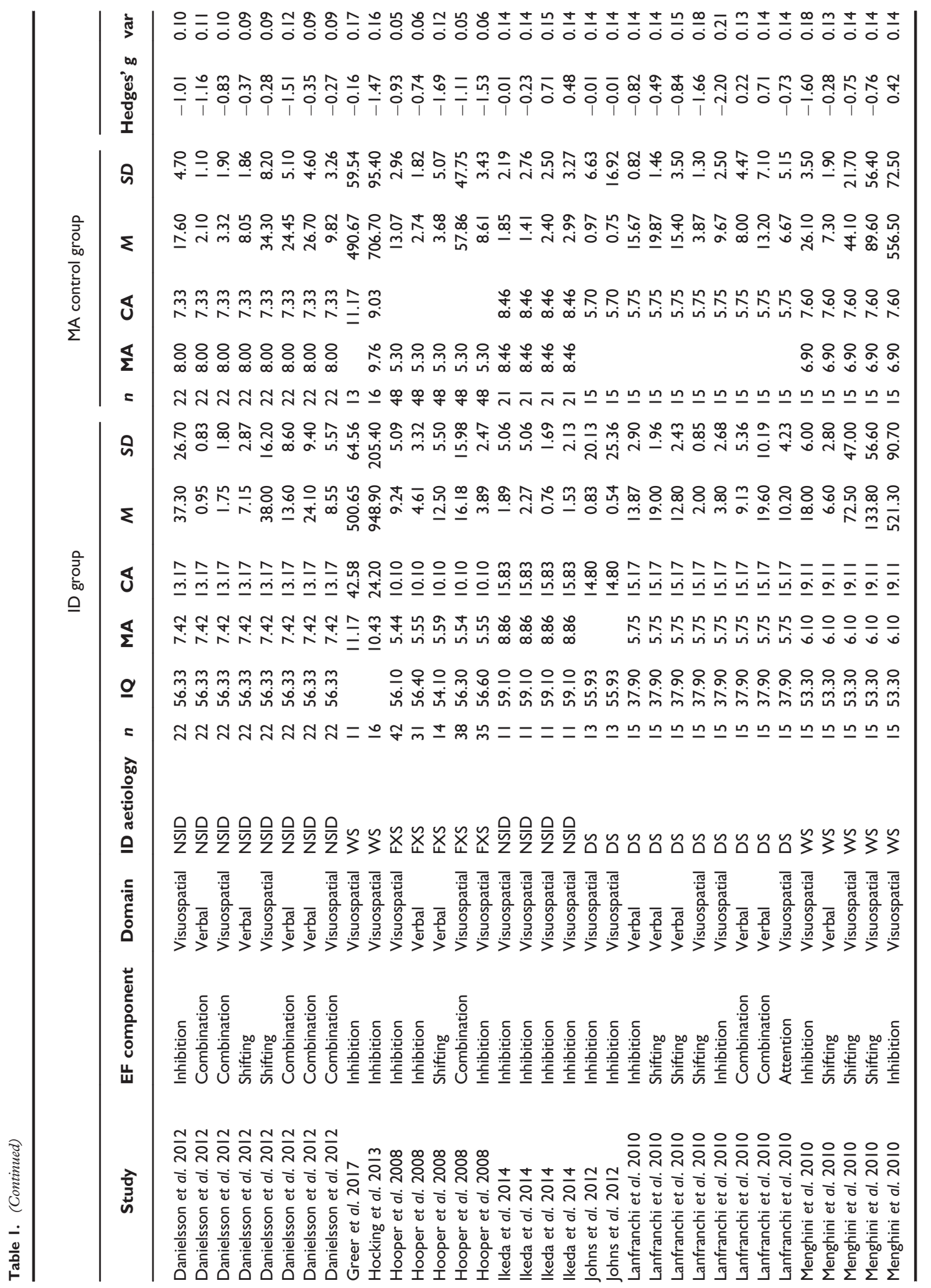

(C) 202 I The Authors. Journal of Intellectual Disability Research published by MENCAP and International Association of the Scientific Study of Intellectual and Developmental Disibilities and John Wiley \& Sons Ltd. 


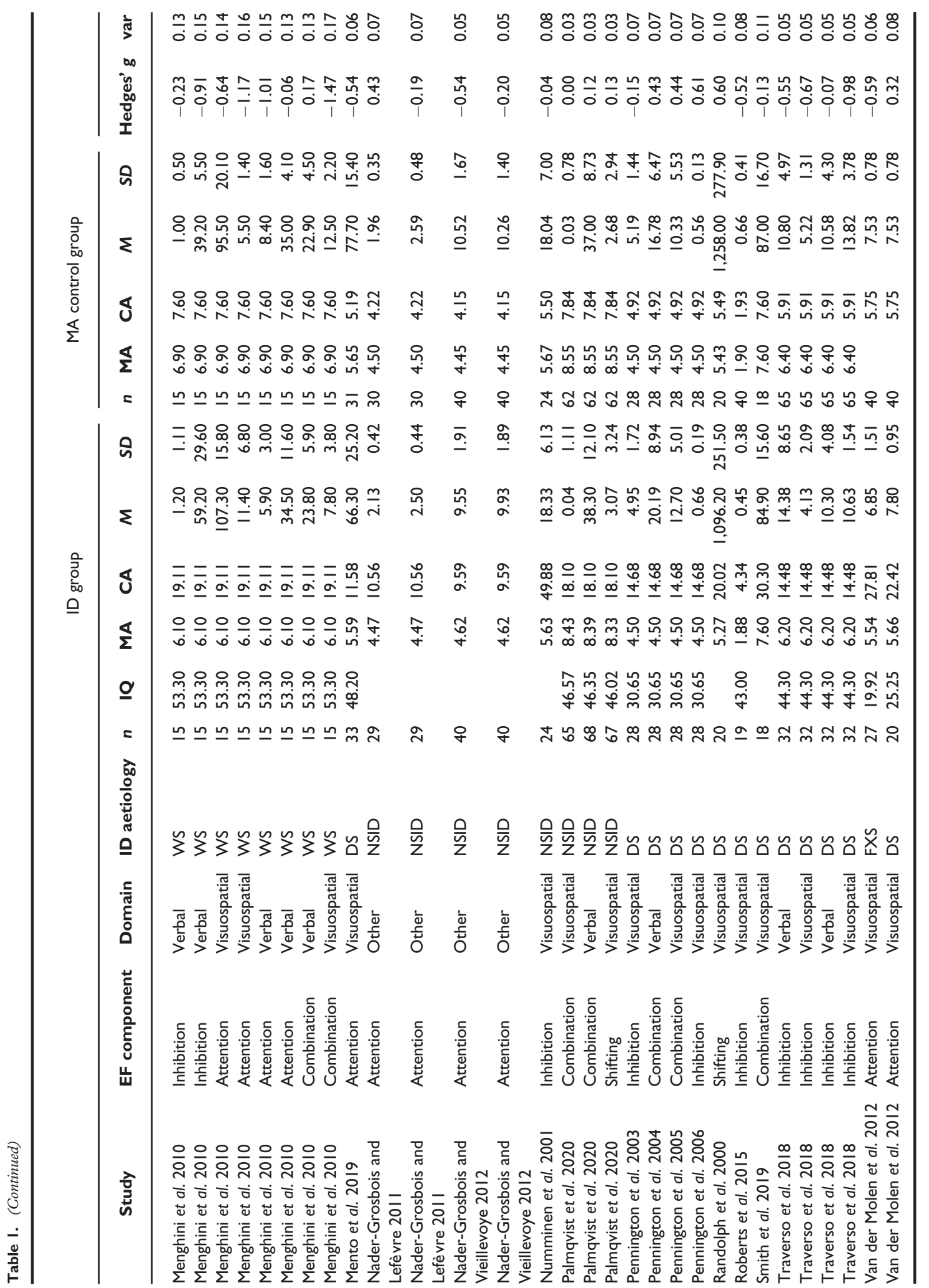

(C) 202 I The Authors. Journal of Intellectual Disability Research published by MENCAP and International Association of the Scientific Study of Intellectual and Developmental Disibilities and John Wiley \& Sons Ltd. 
Altogether 69 different EF tests (I 8 tests for the 24 shifting measures, 9 tests for the 16 attention measures, and 28 tests for the 37 inhibition measures) were used; refer to Table 2 for details.

Overall, the ID group performed significantly lower than the MA controls, $g(k=99)=-0.34,[-0.53$, -0.16], $P=<0.001$. Figure 2 shows a forest plot of the meta-analysis. The range of the effect sizes was large $[-2.20$, I.I5]. The heterogeneity of the examined effect sizes was statistically significant $Q$ (98) $=390.57, P<0.00 \mathrm{I}$, and the estimation of the proportion of observed variation reflecting true variation between effect sizes was $I^{2}=76 \%(49 \%$ within and 28 between studies), which is large ( $>75 \%$ ) according to Higgins et al. (2003). A large $I^{2}$ is an indication that moderator analyses are suitable.

The planned moderator analyses showed a significant moderating effect of ID aetiology (NSID, DS, WS and FXS), but not for EF component; refer to Table 3 for details on all moderator effects. The ID aetiology moderator reduced the between-study variance marginally ( $8 \%$ ) and was followed up with subgroup analyses for the different ID subgroups. The smallest effect size was found for DS, $g$ $(k=32)=-0.15,[-0.44,0.14], P=0.304$, and NSID, $g(k=28)=-0.22,[-0.46,0.02], P=0.068$, but was larger for WS $g(k=33)=-0.63,[-0.86$, -0.40 ], $P<0.001$ and FXS $g(k=6)=-0.97$, [-I.65, -0.29], $P=0.014$. Only the subgroups WS and FXS were statistically significantly $<0$, but the NSID group was close. Because the planned moderators only explained a small part of the estimated true variance, exploratory moderator analyses were carried out for EF domain (verbal and visuospatial) and three variables in the ID group: chronological age, mental age and IQ, but none of the moderators were significant; refer to Table 3 for details.

Publication bias was indicated with a significant Ranktest (Kendall's tau $=-0.19, P=0.005$ ). A visual inspection of the funnel plot in Figure 3 does not indicate publication bias, as most studies lie symmetrically around the overall effect. However, the pattern of the plot is unusual. The outmost dashed line encloses the triangle, within which $99 \%$ of studies are expected to lie in the absence of bias and heterogeneity. In our case, 22 out of 99 data points lie outside this line. We conclude from this that publication bias is probably not a major problem, but there seems to be large heterogeneity.

(C) 202I The Authors. Journal of Intellectual Disability Research published by MENCAP and International Association of the Scientific Study of Intellectual and Developmental Disibilities and John Wiley \& Sons Ltd. 
M. Spaniol \& H. Danielsson - Meta-analysis of executive functions

Table 2 Information on the tests and quality of the studies included

\begin{tabular}{|c|c|c|c|c|c|c|}
\hline Study & Test & Matching & Power & Reliability & $\begin{array}{c}\text { Established } \\
\text { test }\end{array}$ & Index \\
\hline Borella et al. 2013 & Animal Stroop adapted version & 0.00 & 0.45 & 0 & 2 & 4 \\
\hline Borella et al. 2013 & Proactive interference task & 0.00 & 0.45 & 0 & I & 3 \\
\hline Borella et al. 2013 & Directed forgetting & 0.00 & 0.45 & 0 & I & 3 \\
\hline Carney et al. 2013 & Verbal Inhibition Motor Inhibition task verbal & -0.53 & 0.55 & 2 & 2 & 5 \\
\hline Carney et al. 2013 & Verbal Inhibition Motor Inhibition task motor & -0.53 & 0.55 & 2 & 2 & 5 \\
\hline Carney et al. 2013 & Nepsy-II Word generation & -0.53 & 0.55 & 2 & 2 & 5 \\
\hline Carney et al. 2013 & D-KEFS design fluency & -0.53 & 0.55 & 2 & 2 & 5 \\
\hline Carney et al. 2013 & D-KEFS category switching & -0.53 & 0.55 & 2 & 2 & 5 \\
\hline Carney et al. 2013 & D-KEFS switching version of design fluency & -0.53 & 0.55 & 2 & 2 & 5 \\
\hline Carney et al. 2013 & VIMI verbal & 0.19 & 0.54 & 2 & 2 & 7 \\
\hline Carney et al. 2013 & VIMI motor & 0.19 & 0.54 & 2 & 2 & 7 \\
\hline Carney et al. 2013 & Category fluency & 0.19 & 0.54 & 2 & 2 & 7 \\
\hline Carney et al. 2013 & D-KEFS design fluency & 0.19 & 0.54 & 2 & 2 & 7 \\
\hline Carney et al. 2013 & D-KEFS category switching & 0.19 & 0.54 & 2 & 2 & 7 \\
\hline Carney et al. 2013 & D-KEFS switching version of design fluency & 0.19 & 0.54 & 2 & 2 & 7 \\
\hline Carretti et al. 2010 & Updating word span & -0.22 & 0.58 & 0 & I & 3 \\
\hline Clunies-Ross 1972 & Extradimensional shift & -0.34 & 0.72 & 0 & 0 & 2 \\
\hline Clunies-Ross 1972 & First reversal & -0.34 & 0.72 & 0 & 0 & 2 \\
\hline Clunies-Ross 1972 & Stereotype shift & -0.34 & 0.72 & 0 & 0 & 2 \\
\hline $\begin{array}{l}\text { Corter and } \\
\text { McKinney (1968) }\end{array}$ & Cognitive flexibility test battery of 5 tasks & 0.32 & 0.40 & 2 & 0 & 3 \\
\hline Costanzo et al. 2013 & BVN auditory selective attention & -0.22 & 0.39 & 0 & 2 & 3 \\
\hline Costanzo et al. 2013 & Score task & -0.22 & 0.39 & 0 & 2 & 3 \\
\hline Costanzo et al. 2013 & Sky search & -0.22 & 0.39 & 0 & 2 & 3 \\
\hline Costanzo et al. 2013 & Bells test & -0.22 & 0.39 & 0 & 2 & 3 \\
\hline Costanzo et al. 2013 & Tower of London & -0.22 & 0.39 & 0 & 2 & 3 \\
\hline Costanzo et al. 2013 & Category Fluency Test & -0.22 & 0.39 & 0 & 2 & 3 \\
\hline Costanzo et al. 2013 & Weigl Colour Form Sort Test & -0.22 & 0.39 & 0 & 2 & 3 \\
\hline Costanzo et al. 2013 & Category Fluency Test alternative version & -0.22 & 0.39 & 0 & 2 & 3 \\
\hline Costanzo et al. 2013 & Trail making test & -0.22 & 0.39 & 0 & 2 & 3 \\
\hline Costanzo et al. 2013 & Forma forma task & -0.22 & 0.39 & 0 & 2 & 3 \\
\hline Costanzo et al. 2013 & Stroop & -0.22 & 0.39 & 0 & I & 2 \\
\hline Costanzo et al. 2013 & Go/no-go task & -0.22 & 0.39 & 0 & 2 & 3 \\
\hline Danielsson et al. 2012 & Verbal Inhibition Motor Inhibition task verbal & -0.37 & 0.49 & 0 & 2 & 3 \\
\hline Danielsson et al. 2012 & Verbal Inhibition Motor Inhibition task motor & -0.37 & 0.49 & 0 & 2 & 3 \\
\hline Danielsson et al. 2012 & D-KEFS sorting & -0.37 & 0.49 & 0 & 2 & 3 \\
\hline Danielsson et al. 2012 & D-KEFS sorting & -0.37 & 0.49 & 0 & 2 & 3 \\
\hline Danielsson et al. 2012 & Delis-Kaplan Category fluency switching & -0.37 & 0.49 & 0 & 2 & 3 \\
\hline Danielsson et al. 2012 & CANTAB ID ED & -0.37 & 0.49 & 0 & 2 & 3 \\
\hline Danielsson et al. 2012 & D-KEFS letter fluency & -0.37 & 0.49 & 0 & 2 & 3 \\
\hline Danielsson et al. 2012 & D-KEFS category fluency & -0.37 & 0.49 & 0 & 2 & 3 \\
\hline Danielsson et al. 2012 & D-KEFS design fluency & -0.37 & 0.49 & 0 & 2 & 3 \\
\hline Greer et al. 2017 & Oddball & 0.10 & 0.32 & 0 & I & 3 \\
\hline Hocking et al. 2013 & Go/no-go task & 0.31 & 0.40 & 0 & i & 3 \\
\hline Hooper et al. 2008 & Day-night & 0.24 & 0.76 & 0 & 2 & 4 \\
\hline Hooper et al. 2008 & Self-correction on The Contingency Naming Test & 0.45 & 0.69 & 0 & 2 & 3 \\
\hline Hooper et al. 2008 & The Contingency Naming Test subtest 3 errors & 0.54 & 0.49 & 0 & 2 & 2 \\
\hline Hooper et al. 2008 & WJ Planning & 0.46 & 0.74 & 0 & 2 & 3 \\
\hline Hooper et al. 2008 & Nepsy Tower & 0.46 & 0.72 & 0 & 2 & 3 \\
\hline Ikeda et al. 2014 & Real Animal Size Test control condition & 0.23 & 0.37 & 0 & 2 & 3 \\
\hline Ikeda et al. 2014 & Real Animal Size Test incongruent condition & 0.23 & 0.37 & 0 & 2 & 3 \\
\hline Ikeda et al. 2014 & Pictorial Animal Size Test control condition & 0.23 & 0.37 & 0 & 2 & 3 \\
\hline Ikeda et al. 2014 & Pictorial Animal Size Test incongruent condition & 0.23 & 0.37 & 0 & 2 & 3 \\
\hline Johns et al. 2012 & Animal reverse categorisation task & & 0.36 & 0 & I & I \\
\hline
\end{tabular}

(C) 202I The Authors. Journal of Intellectual Disability Research published by MENCAP and International Association of the Scientific Study of Intellectual and Developmental Disibilities and John Wiley \& Sons Ltd. 
M. Spaniol \& H. Danielsson - Meta-analysis of executive functions

Table 2. (Continued)

\begin{tabular}{|c|c|c|c|c|c|c|}
\hline Study & Test & Matching & Power & Reliability & $\begin{array}{c}\text { Established } \\
\text { test }\end{array}$ & Index \\
\hline Johns et al. 2012 & Hand reverse categorisation task & & 0.36 & 0 & 1 & I \\
\hline Lanfranchi et al. 2010 & Day-night & & 0.38 & 0 & 2 & 2 \\
\hline Lanfranchi et al. 2010 & Rule Shift Card Test I & & 0.38 & 0 & 2 & 2 \\
\hline Lanfranchi et al. 2010 & Rule Shift Card Test 2 & & 0.38 & 0 & 2 & 2 \\
\hline Lanfranchi et al. 2010 & Modified Card Sorting Test & & 0.38 & 0 & 2 & 2 \\
\hline Lanfranchi et al. 2010 & Tower of London & & 0.38 & 0 & 2 & 2 \\
\hline Lanfranchi et al. 2010 & FAS verbal fluency & & 0.38 & 0 & 2 & 2 \\
\hline Lanfranchi et al. 2010 & Category fluency & & 0.38 & 0 & 2 & 2 \\
\hline Lanfranchi et al. 2010 & Self-ordered pointing test & & 0.38 & 0 & 2 & 2 \\
\hline Menghini et al. 2010 & Tower of London & & 0.38 & 0 & 2 & 2 \\
\hline Menghini et al. 2010 & Category Fluency Test alternative version & & 0.38 & 0 & 2 & 2 \\
\hline Menghini et al. 2010 & Trail making test & & 0.38 & 0 & 2 & 2 \\
\hline Menghini et al. 2010 & Forma forma task & & 0.38 & 0 & 2 & 2 \\
\hline Menghini et al. 2010 & Go/no-go task & & 0.38 & 0 & 2 & 2 \\
\hline Menghini et al. 2010 & Stroop & & 0.38 & 0 & I & I \\
\hline Menghini et al. 2010 & OppositeWorld & & 0.38 & 0 & 2 & 2 \\
\hline Menghini et al. 2010 & Bells test & & 0.38 & 0 & 2 & 2 \\
\hline Menghini et al. 2010 & Sky search & & 0.38 & 0 & 2 & 2 \\
\hline Menghini et al. 2010 & Score task & & 0.38 & 0 & 2 & 2 \\
\hline Menghini et al. 2010 & BVN auditory selective attention & & 0.38 & 0 & 2 & 2 \\
\hline Menghini et al. 2010 & Category Fluency Test & & 0.38 & 0 & 2 & 2 \\
\hline Menghini et al. 2010 & Weigl Colour Form Sort Test & & 0.38 & 0 & 2 & 2 \\
\hline Mento et al. 2019 & Top-down and bottom-up temporal attention task & -0.04 & 0.63 & 0 & 2 & 5 \\
\hline $\begin{array}{l}\text { Nader-Grosbois and } \\
\text { Lefèvre } 201 \mathrm{I}\end{array}$ & Scoring grid for self-regulation joint attention & -0.08 & 0.60 & 2 & 2 & 7 \\
\hline $\begin{array}{l}\text { Nader-Grosbois and } \\
\text { Lefèvre } 201 \mathrm{I}\end{array}$ & Scoring grid for self-regulation attention & -0.08 & 0.60 & 2 & 2 & 7 \\
\hline $\begin{array}{l}\text { Nader-Grosbois and } \\
\text { Vieillevoye } 2012\end{array}$ & Scoring grid for self-regulation joint attention & 0.17 & 0.72 & 2 & 2 & 7 \\
\hline $\begin{array}{l}\text { Nader-Grosbois and } \\
\text { Vieillevoye } 2012\end{array}$ & Scoring grid for self-regulation attention & 0.17 & 0.72 & 2 & 2 & 7 \\
\hline Numminen et al. $200 \mathrm{I}$ & Tower of Hanoi & -0.02 & 0.52 & 0 & 1 & 4 \\
\hline Palmqvist et al. 2020 & Planning tasks composite & -0.08 & 0.88 & 0 & I & 5 \\
\hline Palmqvist et al. 2020 & Category fluency & -0.11 & 0.88 & 0 & 1 & 5 \\
\hline Palmqvist et al. 2020 & BADS-C Playing cards & -0.16 & 0.88 & 0 & 2 & 6 \\
\hline Pennington et al. 2003 & CANTAB Stockings of Cambridge & 0.01 & 0.58 & 0 & 2 & 5 \\
\hline Pennington et al. 2004 & NEPSY Verbal Fluency & 0.01 & 0.58 & I & 2 & 6 \\
\hline Pennington et al. 2005 & NEPSY Design Fluency & 0.01 & 0.58 & 1 & 2 & 6 \\
\hline Pennington et al. 2006 & Stopping task & 0.01 & 0.58 & 1 & 2 & 6 \\
\hline Randolph et al. 2000 & Modified forced choice RT task & -0.17 & 0.46 & 0 & 0 & 2 \\
\hline Roberts et al. 2015 & A not B task & -0.04 & 0.55 & 0 & 1 & 4 \\
\hline Smith et al. 2019 & Smith task & -0.03 & 0.43 & 0 & 0 & 2 \\
\hline Traverso et al. 2018 & Preschool matching familiar figure task & -0.14 & 0.74 & 2 & 2 & 7 \\
\hline Traverso et al. 2018 & Go/no-go task & -0.14 & 0.74 & 2 & I & 6 \\
\hline Traverso et al. 2018 & Fish flanker task & -0.14 & 0.74 & 2 & I & 6 \\
\hline Traverso et al. 2018 & Dots task & -0.14 & 0.74 & 2 & 2 & 7 \\
\hline Van der Molen et al. 2012 & CANTAB ID ED & & 0.63 & 0 & 2 & 3 \\
\hline Van der Molen et al. 2012 & CANTAB ID ED & & 0.56 & 0 & 2 & 3 \\
\hline Zigler and Unell 1962 & Concept formation tasks & & 0.28 & 0 & 2 & 2 \\
\hline Zigler and Unell 1962 & Concept formation tasks & & 0.28 & 0 & 2 & 2 \\
\hline
\end{tabular}

Note. Matching is the mental age difference (in Cohen's $d$ ) between the intellectual disability (ID) group and the mental age (MA) group, Power is the power to detect a directed group difference (ID $<$ MA) of Cohen's $d=0.5$.

In the Test column, Test battery names are abbreviated: BVN, Batteria per laValutazione Neuropsicologica; CANTAB, Cambridge Neuropsychological Test Automated Battery; D-KEFS, Delis-Kaplan executive function system; WJ, Woodcook-Johnson.

(C) 202I The Authors. Journal of Intellectual Disability Research published by MENCAP and International Association of the Scientific Study of Intellectual and Developmental Disibilities and John Wiley \& Sons Ltd. 


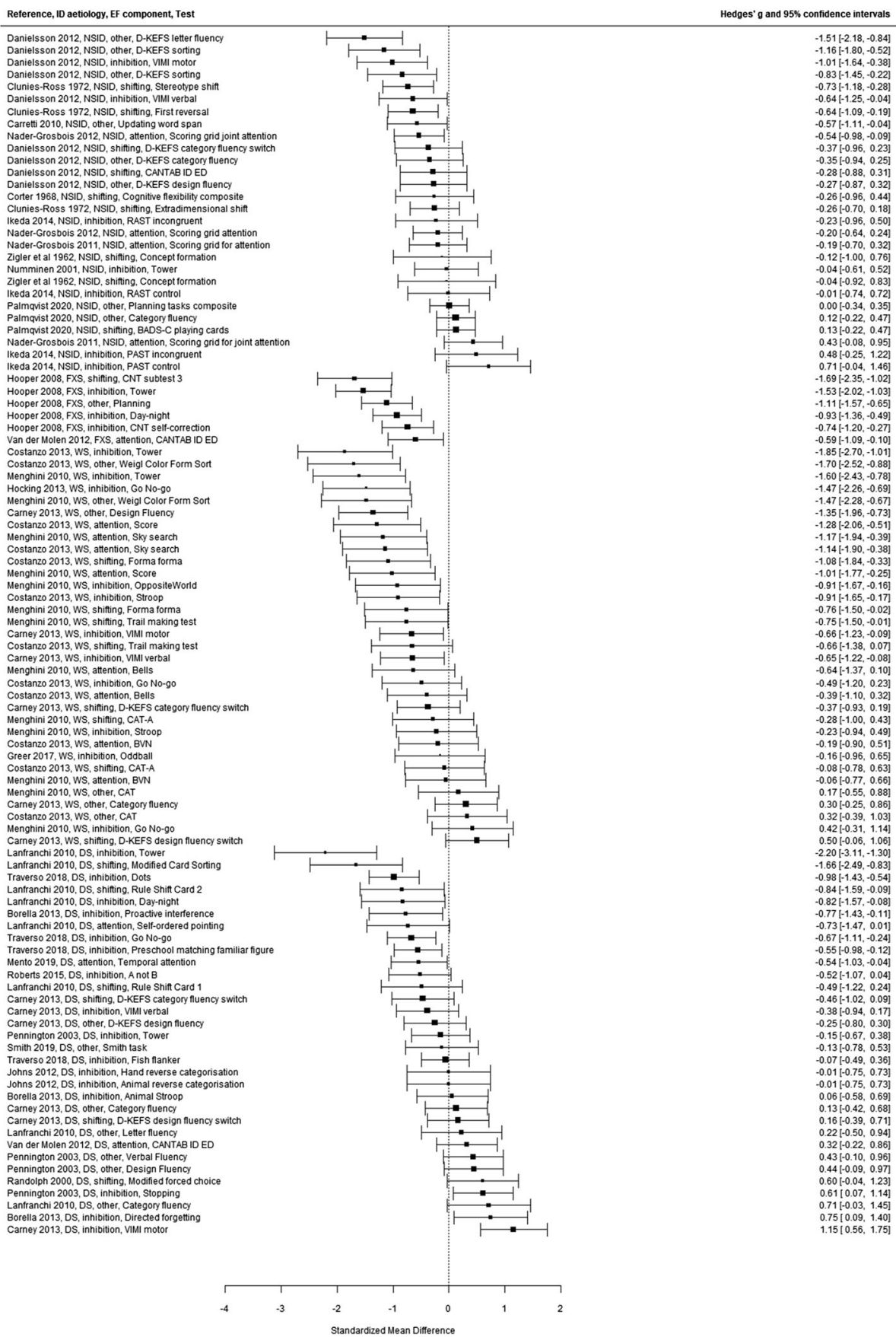

Figure 2. Forest plot of effect sizes (Hedges' $g$ ) and $95 \%$ confidence intervals for all 99 effects included in the meta-analysis, sorted by ID aetiology, and effect size.

A sensitivity analysis was conducted by investigating Cook's distance, but this did not indicate that one particular study had a large impact on the overall results. The largest Cook's distance value was 0.05 , which is well below the cut-off of $\mathrm{I}$. For the moderator analyses and the subgroup analyses, the Cook's distance was the highest (0.49) for the ID aetiology subgroup analysis for the FXS

(C) 202I The Authors. Journal of Intellectual Disability Research published by MENCAP and International Association of the Scientific Study of Intellectual and Developmental Disibilities and John Wiley \& Sons Ltd. 
M. Spaniol \& H. Danielsson - Meta-analysis of executive functions

Table 3 Information on the overall model, subgroup models for the four ID aetiologies and moderator analyses

\begin{tabular}{|c|c|c|c|c|c|c|c|c|c|}
\hline \multirow[b]{2}{*}{ Model } & \multirow[b]{2}{*}{$k$} & \multicolumn{3}{|c|}{ Effect size } & \multicolumn{2}{|c|}{ Heterogeneity $I^{2}$} & \multirow{2}{*}{$\begin{array}{l}\text { Cook's } \\
\text { distance }\end{array}$} & \multicolumn{2}{|c|}{ Test of moderator } \\
\hline & & Hedges' g & $95 \% \mathrm{Cl}$ & $P$ & Within studies & Between studies & & Q & $P$ \\
\hline Overall model & 99 & -0.34 & {$[-0.53,-0.16]$} & $<0.001$ & 49 & 28 & 0.05 & & \\
\hline \multicolumn{10}{|l|}{ Subgroups } \\
\hline Subgroup NSID & 28 & -0.22 & {$[-0.46,0.02]$} & 0.068 & 8 & 50 & 0.09 & & \\
\hline Subgroup DS & 32 & -0.15 & {$[-0.44,0.14]$} & 0.304 & 60 & 19 & 0.07 & & \\
\hline Subgroup WS & 33 & -0.63 & {$[-0.86,-0.4]$} & $<0.001$ & 68 & 0 & 0.12 & & \\
\hline Subgroup FXS & 6 & -0.97 & {$[-1.65,-0.29]$} & 0.014 & 34 & 36 & 0.49 & & \\
\hline \multicolumn{10}{|l|}{ Moderators } \\
\hline EF component & 99 & & & & 49 & 29 & 0.27 & 0.31 & 0.82 \\
\hline ID aetiology & 99 & & & & 52 & 20 & 0.22 & 4.34 & 0.01 \\
\hline Chronological age & 96 & & & & 49 & 28 & 0.10 & 0.12 & 0.73 \\
\hline Domain & 99 & & & & 45 & 32 & 0.24 & 1.51 & 0.23 \\
\hline Mental age & 97 & & & & 48 & 29 & 0.46 & 0.27 & 0.60 \\
\hline IQ & 89 & & & & 52 & 25 & 0.38 & 2.12 & 0.15 \\
\hline \multicolumn{10}{|l|}{ Quality } \\
\hline Quality index & 99 & & & & 51 & 25 & 0.15 & 0.76 & 0.39 \\
\hline Matching & 99 & & & & 52 & 25 & 0.26 & 0.53 & 0.47 \\
\hline Power & 99 & & & & 50 & 26 & 0.12 & 1.22 & 0.27 \\
\hline Reliability & 99 & & & & 49 & 27 & 0.08 & 1.08 & 0.30 \\
\hline Established test & 99 & & & & 49 & 28 & 0.23 & 0.69 & 0.41 \\
\hline
\end{tabular}

$\mathrm{Cl}$, confidence interval; DS, Down Syndrome; EF, executive function; FXS, fragile X syndrome; ID, intellectual disability; NSID, non-specific intellectual disability; WS, Williams syndrome.

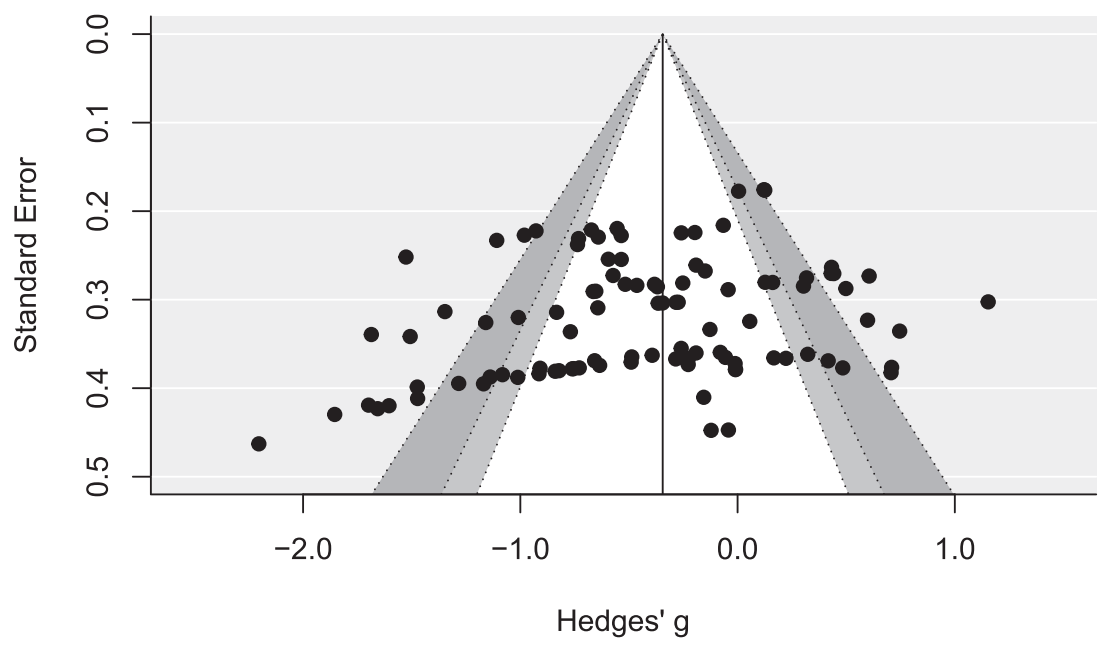

Figure 3. Funnel plot of effect size (Hedge's $g$ ) by the standard error (SE). Each dot represents one effect. group in the Van der Molen et al. (2012) study. This is very high and has influenced the analysis, but it is not surprising that the Cook's distance was the highest for this study because this is the only FXS effect size besides the five Hooper et al. (2008) effect sizes; refer to Table 3 .

The risk of bias assessment results can be found in Table 2. As can be seen, there was a large variation in

(C) 202 I The Authors. Journal of Intellectual Disability Research published by MENCAP and International Association of the Scientific Study of Intellectual and Developmental Disibilities and John Wiley \& Sons Ltd. 
quality. The mean quality index was 3.56. The means for the four quality indicators show that established tasks are used to a high degree (I.73), the MA matching between groups was suboptimal (0.94), few studies reported reliability (0.45) and the power was low (0.43). Analyses were made with the quality indicators as moderators, but neither the quality index nor the four quality indicators were significant moderators; refer to Table 3 for details.

\section{Discussion}

The present work investigated the current literature on EF in individuals with ID compared to MA-controls. The results can be summarised in four main points:

(I) the heterogeneity between studies was large, (2) the ID group performed significantly lower than MA controls, $(g=-0.34)$, (3) the moderator variables investigated could only explain a small part of the heterogeneity among studies and (4) publication bias is probably not a major issue in this field.

Do people with intellectual disability have impaired executive function compared with mental age controls?

The overall effect size shows that the ID group performs statistically significantly lower than the MA controls, which was also found for the subgroups WS and FXS (but not DS and NSID). Although we are not aware of another meta-analysis of EF in people with ID without a dual diagnosis, our results are similar to the findings of $\mathrm{EF}$ in similar groups. A meta-analysis of EF in people with fetal alcohol spectrum disorder and attention deficit hyperactivity disorder shows a significant effect (Kingdon et al. 2016) Hedges' $g$ between -0.52 and -0.94 . A recent meta-analysis by Tungate and Conners (202I) also shows a significant effect, Cohen's $d=-0.87$ of $\mathrm{EF}$ in people with DS, but it should be noted here that their definition of EF differs from the one in our study, they included both short-term memory and working memory but excluded attention tasks.

\section{Do executive function component and intellectual disability aetiology moderate the effect?}

The second research question investigated whether the EF component and the ID aetiology significantly moderated the effect. The heterogeneity was large, as indicated by an overall $I^{2}=76 \%$, which is of similar magnitude as in the other meta-analyses mentioned (i.e. Tungate and Conners 202I, Kingdon et al. 2016 with $\left.I^{2}=-80 \%\right)$. This indicated that moderator analyses were suitable. The moderator ID aetiology was significant. It is specifically interesting that in the subgroups analysis, only WS and FXS (but not NSID and DS) were significantly different from zero.

This finding speaks for differences in the performance of EF tasks across syndromes. This is a finding that has been observed several times before (Carney et al. 2013; Costanzo et al. 2013). These syndrome-specific differences refer to $\mathrm{EF}$ performance in general, but are often expressed even more fine grained as that certain ID aetiologies have specific strengths or weaknesses in specific EF tasks, compared with MA controls. For example, people with WS seem to perform better on verbal inhibition tasks, compared with people with DS but lower on planning tasks (Costanzo et al. 2013). People with DS are considered to have specific strengths in visuospatial tasks but relative weaknesses in shifting and verbal tasks (Costanzo et al. 2013). Compared with other groups with ID, individuals with FXS seem to have strengths in visuospatial tasks (Kogan et al. 2004). Other studies, such as the meta-analysis by Tungate and Conners (202I), showed a significant effect also for the group of people with DS.

Surprisingly, our DS subgroup was non-significant.

Those syndrome-specific findings are highly interesting, but due to the small number of studies in each ID aetiology group within our meta-analysis, inferences have large uncertainty. However, the syndrome-specific differences known from the literature have support from our analyses. The subgroups seem to have specific strengths to some of the EF components included in this meta-analysis, but these analyses are largely underpowered. Moreover, how far these task-specific strengths and weaknesses relate to difficulties in context-specific situations is a different question (Chan et al. 2008).

Surprisingly, the EF component was far from significant. From the literature on people without ID, we expected to find differences between EF components (e.g. Miyake et al. 2000). However, this is consistent with a meta-analysis on EF in DS (Tungate and Conners 202I), which only found one significant difference between EF components (which was short-term memory vs. inhibition). We hypothesize

(C) 202 I The Authors. Journal of Intellectual Disability Research published by MENCAP and International Association of the Scientific Study of Intellectual and Developmental Disibilities and John Wiley \& Sons Ltd. 
M. Spaniol \& H. Danielsson - Meta-analysis of executive functions

that our result (EF component moderator nonsignificant) is due to the large number of different tests used to examine individual EF components.

Our findings (e.g. nonsignificant moderator EF component and subgroups NSID and DS) were potentially biased by our decision to exclude working memory measures. Our initial aim to exclude working memory measures was to avoid it being overrepresented. This could have created an opposite bias, as EF component updating was highly underrepresented in our results. Not having a representable number of updating tasks compared with the other included EF components might have biased the results concerning the moderator $\mathrm{EF}$ component and probably also the results on the different subgroups of ID aetiology, as syndrome specific differences for updating are possible. Our a priori decision on the definition of $\mathrm{EF}$ components makes it difficult to make a direct comparison with some other reviews such as the meta-analysis by Tungate and Conners (202I). Tungate and Conners (202I) included working memory and short-term memory tasks; however, they excluded attention measures. As mentioned in the rationale, $\mathrm{EF}$ can be defined in many ways, and the different definitions are typically vague. It is likely that different findings will be received by using different definitions of $\mathrm{EF}$ and therefore including different $\mathrm{EF}$ components. It is therefore noteworthy that our choice of the definition of EF, which includes inhibition, shifting, updating and attention, might have influenced the findings. Generalising conclusions regarding the overall EF construct should therefore only be made cautiously.

\section{Mental age and chronological age moderators}

None of the exploratory moderator variables chronological age, mental age, IQ and domain had a significant effect on the EF performance. From the literature (e.g. Miyake et al. 200I; Willner et al. 20I0), it is known that there is a relationship between mental age and EF. One methodological challenge with the mental age moderator was that the reporting of mental age and IQ was not consistent. Some studies based their comparison on IQ, others on vocabulary skills and again others on fluid intelligence. Simultaneously, many only reported IQ or mental age. Therefore, some mental age measures were only inferred by the given IQ score.

Even though the moderator IQ was not significant, it is worth mentioning that this might be due to a non-ideal coding of the variable. What was used in this meta-analysis was the mean IQ for every study. However, by reducing the IQ to the mean, a lot of information about the variable gets lost. It would be helpful to be able to divide the studies into mild, moderate and severe ID. However, as most studies have included participants with varying IQ levels, this distinction could not be applied. Still, we would expect differences between people with mild, moderate and severe ID.

As the experimental groups included for DS and FXS have a large range in mean chronological age (4.34 to 30.3 years), we expected that this could have a significant effect on the EF performance. The fastest development in EF abilities is between 5 and 8 years (Goldstein and Naglieri 20I4, p. 9), but EF continues to develop into adulthood. The literature shows that the performance on $\mathrm{EF}$ tasks depends on the developmental stage in life (Luria I980). In this metaanalysis, different steps in the development of EF were covered. Besides, it is known that the IQ of people with DS and FXS tends to decrease between early childhood and young adulthood. It is possible that the development in EF skills was at different levels.

Even though we did not find a significant effect for mental and chronological age, these different complex factors might have added to the heterogeneity of the results. Possibly, there is an underlying structure, which could not be uncovered by our analysis. A more detailed comparison should be made in future studies, investigating EF in ID longitudinally.

\section{Limitations and bias}

One concern when measuring EF is the close link to general cognitive abilities. As EF abilities are assumed to be significantly influenced by the level of intelligence, $\mathrm{EF}$ test results are difficult to interpret towards one specific EF component (Mahone et al. 2002). Many intelligence batteries measure EF, but often not in a detailed way. Therefore, a flexible battery approach is needed to test detailed hypotheses about EF (Goldstein and Naglieri 20I4, p. 379). Most of the papers that were included in the present study

(C) 202 I The Authors. Journal of Intellectual Disability Research published by MENCAP and International Association of the Scientific Study of Intellectual and Developmental Disibilities and John Wiley \& Sons Ltd. 
M. Spaniol \& H. Danielsson - Meta-analysis of executive functions

used a flexible battery approach. This led to further variability in the testing between studies. However, only a few studies included tests of all EF components. Some only examined one EF component, others had several measures per EF component. This can have a bias on the within-studies variance. Another limitation of our study is that we only included laboratory-based measures of EF, opposed to more ecological measures, such as the BRIEF (Gioia et al. 2000). This choice was a functional one, to keep the individual measures as comparable as possible. Still, it comes with a limitation concerning the generalisability to real-world behaviour (Chan et al. 2008), as ecological validity has been criticised for neuropsychological tests (Goldstein 1996).

In consideration of these methodological issues and their influence on the derived effect sizes, studies using standardised EF tasks and large sample sizes may produce more accurate data on the EF performance of individuals with ID. As there is no universally accepted definition of EF, there is also no clear agreement on which specific tasks measure which EF component. In conclusion, research on EF is diverse and often difficult to compare. There are many different EF tasks, which lead to low ecological validity (Ardila 2008). This was also the case here, as tests belonging to several different EF tasks were included. There were 69 different EF tests used to assess the 99 effect sizes included in the metaanalysis. Variations of Tower tests were the most frequently used test, but it was only used for six effect sizes. However, even though Tower tests are similar, they are not identical. Additionally, different measures were reported, for example, seconds to complete, the total number of errors made, levels achieved or the total number of correct responses. Using the standardised mean difference partly adjust for that, but the risk for a task-dependency effect (Welsh 2002) is still high.

The risk of bias assessment identified four studies (Nader-Grosbois and Lefèvre 20I I Nader-Grosbois and Vieillevoye 20I2; Carney et al. 20I3; Traverso et al. 2018) with high quality (score 7 of 8), but some studies only had a score of $\mathrm{I}$. The studies had on average very low power. The median number of participants in the ID group was $2 \mathrm{I}$, which gives $30 \%$ power to detect the average effect size $(g=-0.34)$ found in this meta-analysis. This is very low power and much lower than the rule of thumb of at least $80 \%$.

Another quality issue is the MA matching between the groups. On average, the groups had a difference of Cohen's $d=0.24$, which is of similar magnitude as the effect size found in the meta-analysis. When the groups differ that much in mental age and the studies have low power, it is not surprising that there is a large unexplained variance in this meta-analysis.

None of the publication bias tests indicated that publication bias was present. Studies on cognitive abilities in people with ID are generally publishable even if there are no group differences compared to MA controls for three different reasons. First, both difference and no difference results are interesting for this group because little is known about which cognitive functions are comparably intact and which are delayed. Second, often a control group matched on chronological age is included, and there is a difference between their performance and the ID groups' performance. Third, often many measures are taken in the same study. Typically, group differences vary in magnitude between tests. Efforts to get unpublished results were performed, but only one unpublished study was included, which has since been published (Palmqvist et al. 2020). Given this, it is not surprising that there were no strong signs of publication bias in this field.

\section{Conclusions}

Due to the extremely large heterogeneity, conclusions must be treated warily. This meta-analysis provides further evidence that people with ID perform below their mental age expectation on EF tasks. The heterogeneity in the data was large, which speaks for other moderating effects. When looking at the subgroups, there was only a significant effect for WS and FXS. The high variance levels indicate that research about EF is very heterogeneous. Several methodological issues could cause this. The typical study has a power of only $30 \%$ to detect the average effect size found in this meta-analysis. It is also remarkable that 69 different tests were used to assess the 99 effect sizes included in this meta-analysis. Our definition of EF, including inhibition, shifting, updating and attention might have influenced the findings. Generalising conclusions regarding the overall EF construct should therefore only be made

(C) 202 I The Authors. Journal of Intellectual Disability Research published by MENCAP and International Association of the Scientific Study of Intellectual and Developmental Disibilities and John Wiley \& Sons Ltd. 
cautiously. To further advance the knowledge in this field, future studies should have higher power, be better matched on MA and to a higher degree use a smaller set of EF tests so that the same underlying construct is measured. The deepening of knowledge about EF in ID can help researchers, clinicians, caregivers and parents to improve interventions and help people with ID. The overall aim is to improve the quality of life of individuals with ID and their families.

\section{Acknowledgements}

We thank Marie Annell for help with the screening; Rickard Carlsson, Monica Melby-Lervåg, and Lisa Palmqvist for their helpful comments on earlier versions of this manuscript; and Frederik Aust for help with the papaja package. Open Access funding enabled and organized by Projekt DEAL.

\section{Source of Funding}

No external funding has been used to complete this project.

\section{Conflict of interest}

The authors have no conflicts of interest to report.

\section{Data Availability Statement}

The data that support the findings of this study are openly available in an Open Science Framework project at http://doi.org/IO.I7605/OSF.IO/NJSD3.

\section{References}

Ardila A. (2008) On the evolutionary origins of executive functions. Brain and Cognition 68, 92-9.

Assink M. \& Wibbelink C. J. M. (2016) Fitting three-level meta-analytic models in R: a step-by-step tutorial. The Quantitative Methods for Psychology 12, I54-74.

Aust F. (2018) citr: RStudio add-in to insert markdown citations.

Aust F. \& Barth M. (20I8) Papaja: create APA manuscripts with $\mathrm{R}$ markdown.

Blair C., Zelazo P. D. \& Greenberg M. T. (2005) The measurement of executive function in early childhood. Developmental Neuropsychology 28, 56 I-7I.

*Borella E., Carretti B. \& Lanfranchi S. (2013) Inhibitory mechanisms in Down syndrome: is there a specific or general deficit? Research in Developmental Disabilities 34 65-7I.

Borenstein M., Hedges L. V., Higgins J. P. T. \& Rothstein H. R. (2009) Effect sizes based on means. In: Introduction to Meta-Analysis, pp. 2I-32. John Wiley \& Sons, Ltd., Chichester, UK.

Burack J. A., Iarocci G., Flanagan T. D. \& Bowler D. M. (2004) On mosaics and melting pots: conceptual considerations of comparison and matching strategies. Fournal of Autism and Developmental Disorders 34, 65-73.

${ }^{\star}$ Carney D. P. J., Brown J. H. \& Henry L. A. (2013) Executive function in Williams and Down syndromes. Research in Developmental Disabilities 34, 46-55.

${ }^{\star}$ Carretti B., Belacchi C. \& Cornoldi C. (2010) Difficulties in working memory updating in individuals with intellectual disability. Fournal of Intellectual Disability Research 54, 337-45.

Carter E. C., Schönbrodt F. D., Gervais W. M. \& Hilgard J. (2017) Correcting for bias in psychology: a comparison of meta-analytic methods. Advances in Methods and Practices in Psychological Science 2, II 5-44.

Champely, S. (2020) Pwr: basic functions for power analysis. Available at: https://CRAN.R-project.org/package=pwr

Chan R., Shum D., Toulopoulou T. \& Chen E. (2008) Assessment of executive functions: review of instruments and identification of critical issues. Archives of Clinical Neuropsychology 23, 20I-I6.

${ }^{\star}$ Clunies-Ross G. G. (1972) Rigidity in the retarded: a brief review and some recent data. Fournal of Intellectual and Developmental Disability 2, 106-10.

Cook R. D. (1979) Influential observations in linear regression. Fournal of the American Statistical Association 74, I69-74.

*Corter H. M. \& McKinney J. D. (1968) Flexibility training with educable retarded and bright normal children. American fournal of Mental Deficiency 72, 603-9.

${ }^{\star}$ Costanzo F., Varuzza C., Menghini D., Addona F., Gianesini T. \& Vicari S. (2013) Executive functions in intellectual disabilities: a comparison between Williams syndrome and Down syndrome. Research in Developmental Disabilities 34, I770-80.

Crumley J. J., Stetler C. A. \& Horhota M. (2014) Examining the relationship between subjective and objective memory performance in older adults: a meta-analysis. Psychology and Aging 29, 250-63.

Danielsson H., Henry L., Messer D., Carney D. P. J. \& Rönnberg J. (20I6) Developmental delays in phonological recoding among children and adolescents with Down syndrome and Williams syndrome. Research in Developmental Disabilities 55, 64-76.

^Danielsson H., Henry L., Messer D. \& Rönnberg J. (20I2) Strengths and weaknesses in executive functioning in children with intellectual disability. Research in Developmental Disabilities 33, 600-7.

(C) 202 I The Authors. Journal of Intellectual Disability Research published by MENCAP and International Association of the Scientific Study of Intellectual and Developmental Disibilities and John Wiley \& Sons Ltd. 
M. Spaniol \& H. Danielsson - Meta-analysis of executive functions

Danielsson H., Henry L., Rönnberg J. \& Nilsson L.-G. (2010) Executive functions in individuals with intellectual disability. Research in Developmental Disabilities 3I, I299-304.

Danielsson H., Zottarel V., Palmqvist L. \& Lanfranchi S. (2015) The effectiveness of working memory training with individuals with intellectual disabilities - a meta-analytic review. Frontiers in Psychology 6, I230.

Diamond A. (2013) Executive functions. Annual Review of Psychology 64, 135-68.

Gioia G. A., Isquith P. K., Guy S. C. \& Kenworthy L. (2000) Behavior Rating Inventory of Executive Function: BRIEF. Psychological Assessment Resources, Odessa, FL.

Goldstein G. (1996) Functional considerations in neuropsychology. In: Ecological Validity of Neuropsychological Testing, pp. 75-89. Gr Press/St Lucie Press, Inc., Delray Beach, FL, England.

Goldstein S. \& Naglieri J. A. (eds) (2014) Handbook of Executive Functioning. Springer-Verlag, New York.

${ }^{\star}$ Greer J. M. H., Hamilton C., McMullon M. E. G., Riby D. M. \& Riby L. M. (20I7) An event related potential study of inhibitory and attentional control in Williams syndrome adults. PLOS ONE I2, eoI70I80.

Henry L. (20II) The Development of Working Memory in Children. SAGE Publications, California.

Higgins J. P. T. \& Thompson S. G. (2002) Quantifying heterogeneity in a meta-analysis. Statistics in Medicine 2I, I539-58.

Higgins J. P. T., Thompson S. G., Deeks J. J. \& Altman D. G. (2003) Measuring inconsistency in meta-analyses. BMF 327, 557-60.

${ }^{\star}$ Hocking D. R., Thomas D., Menant J. C., Porter M. A., Smith S., Lord S. R. et al. (2013) The interplay between executive control and motor functioning in Williams syndrome. Developmental Science 16, 428-42.

${ }^{\star}$ Hooper S. R., Hatton D., Sideris J., Sullivan K., Hammer J., Schaaf J. et al. (2008) Executive functions in young males with fragile $\mathrm{X}$ syndrome in comparison to mental age-matched controls: baseline findings from a longitudinal study. Neuropsychology 22, 36-47.

*Ikeda Y., Okuzumi H. \& Kokubun M. (2014) Inhibitory control in children with intellectual disabilities with and without autism spectrum disorders in animal size tests. International Fournal of Developmental Disabilities 6o, 80-8.

Jarrold C. \& Brock J. (2004) To match or not to match? Methodological issues in autism-related research. fournal of Autism and Developmental Disorders 34, 8I-6.

`Johns A., Homewood J., Stevenson R. \& Taylor A. (20I2) Implicit and explicit olfactory memory in people with and without Down syndrome. Research in Developmental Disabilities 33, 583-93.

Kingdon D., Cardoso C. \& McGrath J. J. (2016) Research review: executive function deficits in fetal alcohol spectrum disorders and attention-deficit/hyperactivity disorder a meta-analysis. Fournal of Child Psychology and Psychiatry 57, II6-3I.
Klein O., Hardwicke T. E., Aust F., Breuer J., Danielsson H., Hofelich Mohr A. et al. (2018) A practical guide for transparency in psychological science. Collabra: Psychology 4, 20.

Kogan C. S., Bertone A., Cornish K., Boutet I., Der Kaloustian V. M. et al. (2004) Integrative cortical dysfunction and pervasive motion perception deficit in Fragile X syndrome. Neurology 63, 1634-9.

Lajeunesse M. J. (2016) Facilitating systematic reviews, data extraction, and meta-analysis with the metagear package for $\mathrm{r}$. Methods in Ecology and Evolution 7, 323-30.

*Lanfranchi S., Jerman O., Dal Pont E., Alberti A. \& Vianello R. (20I0) Executive function in adolescents with Down Syndrome. Fournal of Intellectual Disability Research 54, 308-I9.

Liberati A., Altman D. G., Tetzlaff J., Mulrow C., Gøtzsche P. C., Ioannidis J. P. A. et al. (2009) The PRISMA statement for reporting systematic reviews and meta-analyses of studies that evaluate health care interventions: explanation and elaboration. PLoS Medicine 6, eI000100.

Lifshitz H., Kilberg E. \& Vakil E. (2016) Working memory studies among individuals with intellectual disability: an integrative research review. Research in Developmental Disabilities 59, I47-65.

Lipsey M. W. \& Wilson D. B. (200I) Practical Meta-analysis. SAGE Publications Inc.

Luria A. R. (1980) Higher Cortical Functions in Man, 2nd edn. Springer US.

Mahone E. M., Hagelthora K. M., Cutting L. E., Schuerholz L. J., Pelletier S. F. et al. (2002) Effects of IQ on executive function measures in children with ADHD. Child Neuropsychology 8, 52-65.

Miller D. C. \& Maricle D. E. (2012) The emergence of neuropsychological constructs into tests of intelligence and cognitive abilities. In: Contemporary Intellectual Assessment: Theories, Tests, and Issues (ed. P. L. Flanagan), 3rd edn, pp. 800-19. Guilford Press, New York.

*Menghini D., Addona F., Costanzo F. \& Vicari S. (2010) Executive functions in individuals with Williams syndrome. Fournal of Intellectual Disability Research 54, 418-32.

^Mento G., Scerif G., Granziol U., Franzoi M. \& Lanfranchi S. (2019) Dissociating top-down and bottom-up temporal attention in Down syndrome: a neurocostructive perspective. Cognitive Development 49, 8I-93.

Messer D. J., Henry L. A. \& Danielsson H. (202I) Children with intellectual and developmental disabilities: issues about matching, recruitment and group comparisons. Submitted Manuscript.

Miyake A., Friedman N. P., Emerson M. J., Witzki A. H., Howerter A. \& Wager T. D. (2000) The unity and diversity of executive functions and their contributions to complex "frontal lobe" tasks: a latent variable analysis. Cognitive Psychology 4I, 49-100.

(C) 202 I The Authors. Journal of Intellectual Disability Research published by MENCAP and International Association of the Scientific Study of Intellectual and Developmental Disibilities and John Wiley \& Sons Ltd. 
Miyake A., Friedman N. P., Rettinger D. A., Shah P. \& Hegarty M. (200I) How are visuospatial working memory, executive functioning, and spatial abilities related? A latent-variable analysis. Fournal of Experimental Psychology: General 130, 62 I-40.

Moher D., Liberati A., Tetzlaff J., Altman D. G. \& Group, T. P (2009) Preferred Reporting Items for Systematic Reviews and Meta-Analyses: the PRISMA statement. PLoS Medicine 6, eIoooo97.

*Nader-Grosbois N. \& Lefèvre N. (20II) Self-regulation and performance in problem-solving using physical materials or computers in children with intellectual disability. Research in Developmental Disabilities 32, I492-505.

*Nader-Grosbois N. \& Vieillevoye S. (20I2) Variability of self-regulatory strategies in children with intellectual disability and typically developing children in pretend play situations. Fournal of Intellectual Disability Research: FIDR 56, I40-56.

^Numminen H., Lehto J. E. \& Ruoppila I. (200I) Tower of Hanoi and working memory in adult persons with intellectual disability. Research in Developmental Disabilities 22, 373-87.

^Palmqvist L., Danielsson H., Jönsson A. \& Rönnberg J. (2020) Cognitive abilities and life experience in everyday planning in individuals with intellectual disabilities: support for the developmental delay model. Fournal of Intellectual Disability Research 64, 209-20.

^Pennington B. F., Moon J., Edgin J., Stedron J. \& Nadel L. (2003) The neuropsychology of Down syndrome: evidence for hippocampal dysfunction. Child Development 74, 75-93.

$\mathrm{R}$ Core Team (2019) $R$ : a language and environment for statistical computing. R Foundation for Statistical Computing, Vienna, Austria.

${ }^{\star}$ Randolph B. \& Burack J. A. (2000) Visual filtering and covert orienting in persons with Down syndrome. International Fournal of Behavioral Development 24, I67-72.

${ }^{\star}$ Roberts L. V. \& Richmond J. L. (2015) Preschoolers with Down syndrome do not yet show the learning and memory impairments seen in adults with Down syndrome. Developmental Science I8, 404-19.

RStudio Team (20I6) RStudio: Integrated Development Environment for $R$. RStudio, Inc., Boston, MA.

Schalock R. L., Borthwick-Duffy S. A., Bradley V. J., Buntinx W. H., Coulter D. L., Craig E. M. et al. (2010) Intellectual Disability: Definition, Classification, and Systems of Supports. AAIDD, Washington, DC.

Shiffrin R. M. (1988) Attention. In: Stevens' Handbook of Experimental Psychology: Perception and Motivation; Learning and Cognition, 2nd edn, vol. I-2, pp. 739-8II. Oxford, England, John Wiley \& Sons.

^Smith E., Hedge C. \& Jarrold C. (2019) A novel framework to measure executive function in Down syndrome with applications for early clinical diagnosis of dementia.
American fournal on Intellectual and Developmental Disabilities I24, 354-73.

Snyder H. R., Miyake A. \& Hankin B. L. (2015) Advancing understanding of executive function impairments and psychopathology: Bridging the gap between clinical and cognitive approaches. Frontiers in Psychology 6, 328.

Sterne J. A. C., Sutton A. J., Ioannidis J. P. A., Terrin N., Jones D. R., Lau J. et al. (20II) Recommendations for examining and interpreting funnel plot asymmetry in meta-analyses of randomised controlled trials. BMF 343, d4002.

Thurstone L. L. (1926) The mental age concept. Psychological Review 33, 268-78.

*Traverso L., Fontana M., Usai M. C. \& Passolunghi M. C. (2018) Response inhibition and interference suppression in individuals with Down syndrome compared to typically developing children. Frontiers in Psychology 9, 660.

Tungate A. S. \& Conners F. A. (202I) Executive function in Down syndrome: a meta-analysis. Research in Developmental Disabilities 108, 103802.

Van den Noortgate W., López-López J. A., Marín-Martínez F. \& Sánchez-Meca J. (2013) Three-level meta-analysis of dependent effect sizes. Behavior Research Methods 45, 576-94.

*Van der Molen M. J. W., Van der Molen M. W., Ridderinkhof K. R., Hamel B. C. J., Curfs L. M. G. \& Ramakers G. J. A. (20I2) Attentional set-shifting in fragile $\mathrm{X}$ syndrome. Brain and Cognition 78, 206-I 7.

Viechtbauer W. (2010) Conducting meta-analyses in R with the metafor package. Fournal of Statistical Software 36, I-48.

Welsh M. C. (2002) Developmental and clinical variations in executive functions. In: Developmental Variations in Learning: Applications to Social, Executive Function, Language and Reading Skills (eds D. L. Molfese \& V. J. Molfese), pp. I39-85. Lawrence Erlbaum Associates Publishers, Mahwah, NJ, US.

Westgate M. J. (2019) Revtools: an R package to support article screening for evidence synthesis. Research Synthesis Methods Io, 606-I4.

Willner P., Bailey R., Parry R. \& Dymond S. (2010) Evaluation of executive functioning in people with intellectual disabilities. Fournal of Intellectual Disability Research 54, 366-79.

Zigler E. \& Balla D. (I982) Introduction: the developmental approach to mental retardation. In: Mental Retardation: The Developmental Difference Controversy (eds E. Zigler \& D. Balla), pp. 3-8. Lawrence Erlbaum Associates, Hillsdale, NJ.

*Zigler E. \& Unell E. (1962) Concept-switching in normal and feebleminded children as a function of reinforcement. American fournal of Mental Deficiency 66, $65 \mathrm{I}-7$.

(C) 202 I The Authors. Journal of Intellectual Disability Research published by MENCAP and International Association of the Scientific Study of Intellectual and Developmental Disibilities and John Wiley \& Sons Ltd. 


\section{A: Appendix}

\section{PRISMA 2009 Checklist}

For the process of the meta-analysis, this checklist was used as a guideline. The checklist contains information about what information is included in this document and where it can be found (Liberati et al. 2009). ${ }^{\text {I, } 2}$

\begin{tabular}{|c|c|c|c|}
\hline Section/topic & $\#$ & Checklist item & $\begin{array}{l}\text { Reported } \\
\text { on page \# }\end{array}$ \\
\hline \multicolumn{4}{|l|}{ Title } \\
\hline Title & I & $\begin{array}{l}\text { Identify the report as a systematic review, meta-analysis, or } \\
\text { both. }\end{array}$ & I \\
\hline \multicolumn{4}{|l|}{ Abstract } \\
\hline Structured summary & 2 & $\begin{array}{l}\text { Provide a structured summary including, as applicable: } \\
\text { background; objectives; data sources; study eligibility criteria, } \\
\text { participants, and interventions; study appraisal and synthesis } \\
\text { methods; results; limitations; conclusions and implications of } \\
\text { key findings; systematic review registration number. }\end{array}$ & $\mathrm{I}-2$ \\
\hline \multicolumn{4}{|l|}{ Introduction } \\
\hline Rationale & 3 & $\begin{array}{l}\text { Describe the rationale for the review in the context of what is } \\
\text { already known. }\end{array}$ & $3-5$ \\
\hline Objectives & 4 & $\begin{array}{l}\text { Provide an explicit statement of questions being addressed } \\
\text { with reference to participants, interventions, comparisons, } \\
\text { outcomes, and study design (PICOS). }\end{array}$ & $5-6$ \\
\hline \multicolumn{4}{|l|}{ Methods } \\
\hline Protocol and registration & 5 & $\begin{array}{l}\text { Indicate if a review protocol exists, if and where it can be } \\
\text { accessed (e.g. Web address), and, if available, provide } \\
\text { registration information including registration number. }\end{array}$ & 6 \\
\hline Eligibility criteria & 6 & $\begin{array}{l}\text { Specify study characteristics (e.g. PICOS and length of follow- } \\
\text { up) and report characteristics (e.g. years considered, language } \\
\text { and publication status) used as criteria for eligibility, giving } \\
\text { rationale. }\end{array}$ & $7-8$ \\
\hline Information sources & 7 & $\begin{array}{l}\text { Describe all information sources (e.g. databases with dates of } \\
\text { coverage and contact with study authors to identify additional } \\
\text { studies) in the search and date last searched. }\end{array}$ & $6-7$ \\
\hline Search & 8 & $\begin{array}{l}\text { Present full electronic search strategy for at least one database, } \\
\text { including any limits used, such that it could be repeated. }\end{array}$ & appendix A2 \\
\hline Study selection & 9 & $\begin{array}{l}\text { State the process for selecting studies (i.e. screening, eligibility, } \\
\text { included in systematic review, and, if applicable, included in the } \\
\text { meta-analysis). }\end{array}$ & $6-7$ \\
\hline Data collection process & 10 & $\begin{array}{l}\text { Describe method of data extraction from reports (e.g. piloted } \\
\text { forms, independently, in duplicate) and any processes for } \\
\text { obtaining and confirming data from investigators. }\end{array}$ & 8 \\
\hline Data items & II & & 8 \\
\hline
\end{tabular}

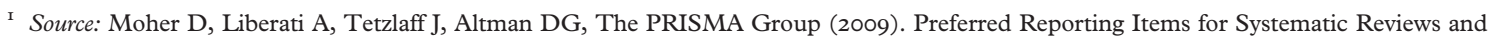
Meta-Analyses: The PRISMA Statement. PLoS Med 6(7): eroooo97. doi: I0.137I/journal.pmedioooo97

2 For more information, visit online (www.prisma-statement.org).

(C) 202 I The Authors. Journal of Intellectual Disability Research published by MENCAP and International Association of the Scientific Study of Intellectual and Developmental Disibilities and John Wiley \& Sons Ltd. 


\begin{tabular}{|c|c|c|c|}
\hline Section/topic & \# & Checklist item & $\begin{array}{l}\text { Reported } \\
\text { on page \# }\end{array}$ \\
\hline & & $\begin{array}{l}\text { List and define all variables for which data were sought } \\
\text { (e.g. PICOS and funding sources) and any assumptions and } \\
\text { simplifications made. }\end{array}$ & \\
\hline Risk of bias in individual studies & 12 & $\begin{array}{l}\text { Describe methods used for assessing risk of bias of individual } \\
\text { studies (including specification of whether this was performed } \\
\text { at the study or outcome level), and how this information is } \\
\text { to be used in any data synthesis. }\end{array}$ & $8-9$ \\
\hline Summary measures & 13 & $\begin{array}{l}\text { State the principal summary measures (e.g. risk ratio and } \\
\text { difference in means). }\end{array}$ & 10 \\
\hline Synthesis of results & 14 & $\begin{array}{l}\text { Describe the methods of handling data and combining results of } \\
\text { studies, if performed, including measures of consistency }\left(\text { e.g. } I^{2}\right) \\
\text { for each meta-analysis. }\end{array}$ & $9-10$ \\
\hline Risk of bias across studies & 15 & $\begin{array}{l}\text { Specify any assessment of risk of bias that may affect the } \\
\text { cumulative evidence (e.g. publication bias and selective } \\
\text { reporting within studies). }\end{array}$ & $9-10$ \\
\hline Additional analyses & 16 & $\begin{array}{l}\text { Describe methods of additional analyses (e.g. sensitivity or } \\
\text { subgroup analyses and meta-regression), if performed, } \\
\text { indicating which were pre-specified. }\end{array}$ & 10 \\
\hline \multicolumn{4}{|c|}{ The } \\
\hline Study selection & 17 & $\begin{array}{l}\text { Give numbers of studies screened, assessed for eligibility, and } \\
\text { included in the review, with reasons for exclusions at each } \\
\text { stage, ideally with a flow diagram. }\end{array}$ & Fig. I,6-7 \\
\hline Study characteristics & 18 & $\begin{array}{l}\text { For each study, present characteristics for which data were } \\
\text { extracted (e.g. study size, PICOS and follow-up period) and } \\
\text { provide the citations. }\end{array}$ & Tab. I, References \\
\hline Risk of bias within studies & 19 & $\begin{array}{l}\text { Present data on risk of bias of each study and, if available, any } \\
\text { outcome level assessment (refer to item 12). }\end{array}$ & $12-13$ \\
\hline Results of individual studies & 20 & $\begin{array}{l}\text { For all outcomes considered (benefits or harms), present, for } \\
\text { each study: (a) simple summary data for each intervention } \\
\text { group (b) effect estimates and confidence intervals, ideally } \\
\text { with a forest plot. }\end{array}$ & Fig. 2, tab. I \\
\hline Synthesis of results & 21 & $\begin{array}{l}\text { Present results of each meta-analysis performed, including } \\
\text { confidence intervals and measures of consistency. }\end{array}$ & Fig. 2, tab. I, I2-14 \\
\hline Risk of bias across studies & 22 & $\begin{array}{l}\text { Present results of any assessment of risk of bias across studies } \\
\text { (refer to item 15). }\end{array}$ & Tab. 2, 13 \\
\hline Additional analysis & 23 & $\begin{array}{l}\text { Give results of additional analyses, if performed [e.g. sensitivity } \\
\text { or subgroup analyses, meta-regression (refer to item 16)]. }\end{array}$ & Tab 3,12-13 \\
\hline \multicolumn{4}{|l|}{ Discussion } \\
\hline Summary of evidence & 24 & $\begin{array}{l}\text { Summarise the main findings including the strength of evidence } \\
\text { for each main outcome; consider their relevance to key groups } \\
\text { (e.g. healthcare providers, users and policy makers). }\end{array}$ & $13-15$ \\
\hline Limitations & 25 & $\begin{array}{l}\text { Discuss limitations at study and outcome level (e.g. risk of bias), } \\
\text { and at review-level (e.g. incomplete retrieval of identified } \\
\text { research and reporting bias). }\end{array}$ & $16-17$ \\
\hline Conclusions & 26 & $\begin{array}{l}\text { Provide a general interpretation of the results in the context of } \\
\text { other evidence, and implications for future research. }\end{array}$ & 18 \\
\hline \multicolumn{4}{|l|}{ Funding } \\
\hline Funding & 27 & $\begin{array}{l}\text { Describe sources of funding for the systematic review and } \\
\text { other support (e.g. supply of data); role of funders for the } \\
\text { systematic review. }\end{array}$ & Author details.docx \\
\hline
\end{tabular}

(C) 202I The Authors. Journal of Intellectual Disability Research published by MENCAP and International Association of the Scientific Study of Intellectual and Developmental Disibilities and John Wiley \& Sons Ltd. 


\section{Full electronic search strategy}

For the PRISMA checklist (8) 'Search', a full electronic search should be given. The additional files can be found online (http://doi.org/IO.I7605/OSF.IO/ $\mathrm{NJSD}_{3}$ )

Pubmed 20I9-08-2I

('intellectual disability'[TIAB] OR 'intellectual disabilities' [TIAB] OR 'mental retardation' [TIAB] OR 'down syndrome'[TIAB] OR 'williams syndrome' [TIAB] OR 'fragile $\mathrm{x}$ '[TIAB] OR 'intellectual disability' $[\mathrm{MeSH}$ Terms]) AND ('executive function' [TIAB] OR 'executive functions'[TIAB] OR 'executive functioning' [TIAB] OR 'executive dysfunction' [TIAB] OR 'shifting' [TIAB] OR 'switching' [TIAB] OR 'updating' [TIAB] OR 'inhibition' [TIAB] OR 'cognitive flexibility' [TIAB] OR 'cognitive control'[TIAB] OR 'executive control'[TIAB] OR 'executive controls' [TIAB] OR 'executive function' [MeSH Terms]) AND english[Language] AND Journal Article[ptyp]

I694 records

Saved in nine files called citationI-200.nbib to citationI60I-I694.nbib

Scopus 20I9-08-2I

(TITLE-ABS-KEY ('intellectual disability') OR TITLE-ABS-KEY ('intellectual disabilities') OR TITLE-ABS-KEY ('mental retardation') OR TITLE-ABS-KEY ('down syndrome’) OR TITLEABS-KEY ('williams syndrome') OR TITLE-ABSKEY ('fragile $x$ ')) AND (TITLE-ABS-KEY ('executive function') OR TITLE-ABS-KEY ('executive functions') OR TITLE-ABS-KEY ('executive functioning') OR TITLE-ABS-KEY ('executive dysfunction') OR TITLE-ABS-KEY ('shifting') OR TITLE-ABS-KEY ('switching') OR TITLE-ABS-KEY ('updating') OR TITLE-ABSKEY ('inhibition') OR TITLE-ABS-KEY ('cognitive flexibility') OR TITLE-ABS-KEY ('cognitive control') OR TITLE-ABS-KEY ('executive control') OR TITLE-ABS-KEY ('executive controls')) AND (LIMIT-TO (DOCTYPE, 'ar')) AND (LIMIT-TO (LANGUAGE, 'English'))

I870 records

Saved in one file called scopusi-I870.bib. This file only contains $\mathrm{I} 869$ records, why a separate file was created for the missing file (maehler et al) called scopus_maehler.bib

Psycinfo 20I9-08-2I

(TX 'intellectual disability' OR TX 'intellectual disabilities' OR TX 'mental retardation' OR TX 'down syndrome' OR TX 'williams syndrome' OR TX 'fragile x' OR SU 'Intellectual Development Disorder') AND (TX 'executive function' OR TX 'executive functions' OR TX 'executive functioning' OR TX 'executive dysfunction' OR TX 'shifting' OR TX 'switching' OR TX ‘updating' OR TX 'inhibition' OR TX ‘cognitive flexibility' OR TX 'cognitive control' OR TX 'executive control' OR TX 'executive controls' OR SU 'executive function')

AND LA english AND PT Peer Reviewed Journal I077 records

Saved in I file called psycinfor-I077.bib

Web of Science core collection 20I9-08-2I

$((\mathrm{TS}=($ 'intellectual disability')

ORTS $=$ ('intellectual disabilities') ORTS $=$ ('mental retardation') ORTS = ('down syndrome')

ORTS = ('williams syndrome') ORTS $=($ (fragile $\mathrm{x}$ ') $)$ AND (TS = ('executive function')

ORTS = ('executive functions') ORTS $=$ ('executive functioning') ORTS = ('executive dysfunction')

ORTS $=$ ('shifting') ORTS $=$ ('switching')

ORTS $=$ ('updating') ORTS = ('inhibition')

ORTS $=$ ('cognitive flexibility') ORTS $=$ ('cognitive control') ORTS = ('executive control')

ORTS $=($ 'executive controls') $)$ )

Plus the limitors LANGUAGE: (English) AND

DOCUMENT TYPES: (Article)

I94I records

Saved in four files named wosI-50I.bib to wosi50II94I

Accepted II August 202 I

\section{Supporting Information}

Additional Supporting Information may be found online in the supporting information tab for this article.

Data Sr: Full text screening with reasons for exclusion.

(C) 202 I The Authors. Journal of Intellectual Disability Research published by MENCAP and International Association of the Scientific Study of Intellectual and Developmental Disibilities and John Wiley \& Sons Ltd. 